Original Article

\title{
Decrease of Both Cofilin and LIM Kinase Phosphorylation in the Skeletal Muscles of Immobilization-induced Atrophy Rats
}

\author{
Mee-Young Kim, PT, MS ${ }^{1)}$, Ju-Hyun Kim, PT, PhD ${ }^{1)}$, Jeong-Uk Lee, PT, MS ${ }^{1)}$, \\ Lim-Kyu Lee, PT, MS ${ }^{1)}$, Seung-Min Yang, PT, MS ${ }^{1)}$, Hye-Joo Jeon, PT, MS ${ }^{1)}$, \\ Won-Deok Lee, PT, MS ${ }^{1)}$, Ji-Woong Noh, PT, MS ${ }^{1)}$, Tae-Hyun Lee, PhD ${ }^{2)}$, \\ Taek-Yong KwaK, PhD ${ }^{3}$, Bokyung Kim, DVM, PhD ${ }^{4}$, Junghwan Kim, PT, $\mathrm{PhD}^{5)^{*}}$ \\ 1) Laboratory of Health Science and Nanophysiotherapy, Department of Physical Therapy, Graduate \\ School, Yongin University, Republic of Korea \\ 2) Department of Combative Martial Arts Training, College of Martial Arts, Yongin University, \\ Republic of Korea \\ 3) Taekwondo Instructor Education, College of Martial Arts, Yongin University, Republic of Korea \\ 4) Institute of Functional Genomics, Department of Physiology, School of Medicine, Konkuk University, \\ Republic of Korea \\ 5) Department of Physical Therapy, College of Public Health and Welfare, Yongin University: Yongin \\ 449-714, Republic of Korea
}

\begin{abstract}
Purpose] Immobilization-induced atrophy is a general phenomenon caused by prolonged muscle disuse associated with orthopaedic conditions. However, changes in the phosphorylation of atrophy-related cofilin and LIM kinases are still poorly understood. In this study, we examined whether or not phosphorylation of cofilin and LIM kinases is altered in the skeletal muscles of rats after 3, 7, 14, and 21 days of cast immobilization. [Methods] We used two-dimensional gel electrophoresis, mass spectrometry, and western blotting to examine protein expression and phosphorylation in atrophied rat gastrocnemius muscles. [Results] The expression of the cofilin was detected in gastrocnemius muscle strips using proteomic analysis. Cast immobilization after 3, 7, 14, and 21 days significantly diminished the phosphorylation of cofilin and LIM kinases. [Conclusion] The present results suggest that cast immobilization-induced atrophy may be in part related to changes in the phosphorylation of cofilin and LIM kinases in rat skeletal muscles.
\end{abstract}

Key words: Cofilin, LIM kinases, Skeletal muscle atrophy

(This article was submitted Aug. 13, 2013, and was accepted Sep. 22, 2013)

\section{INTRODUCTION}

Cofilin is an actin binding protein with a low molecular weight of about $19 \mathrm{kDa}$. It was first extracted and purified from embryonic chick brain extracts, and is ubiquitously expressed protein in eukaryotic cells, where it regulates actin filament dynamics and reorganization, and other functions for cellular viability ${ }^{1-3)}$. Actin filament dynamics and reorganization are fundamental cell activities, which include cell division, morphogenesis, migration, endocytosis, and gene expression ${ }^{4-6)}$. Cofilin binds to fibrous actin changing the fibrous actin to globular actin ${ }^{2}$. This process requires the dephosphorylation of cofilin by phosphatases ${ }^{7,8)}$. Phosphorylation abolishes cofilin activity and inhibits the sever-

*Corresponding author. Junghwan Kim (E-mail: junghwankim3@yongin.ac.kr)

C2014 The Society of Physical Therapy Science. Published by IPEC Inc. This is an open-access article distributed under the terms of the Creative Commons Attribution Non-Commercial No Derivatives (by-ncnd) License $<$ http://creativecommons.org/licenses/by-nc-nd/3.0/> ing function of cofilin ${ }^{9,10)}$, and LIM kinases, a serine kinase, phosphorylates cofilin ${ }^{9,11)}$. A description of the membranes of the LIM kinase family of serine kinases, which include LIM kinase 1 and 2, has been published ${ }^{9}$. Although the exact signaling pathway for the activation of LIM kinases is not fully understood, these proteins regulate actin polymerization via activation and inactivation of cofilin ${ }^{9-11)}$. Skeletal muscle atrophy has proven to be a significant problem in the area of physical therapy rehabilitation ${ }^{12-15)}$. However, changes in the levels of phosphorylation of cofilin and LIM kinases in immobilization-induced atrophy are not fully understood. Therefore, in the present study, we sought to demonstrate the changes in the phosphorylation of cofilin and LIM kinases in the gastrocnemius muscles of rats subjected to cast immobilization.

\section{MATERIALS AND METHODS}

Male Sprague-Dawley rats $(n=15)$ were anaesthetized during the attachment of the plaster of paris casting materi$\mathrm{al}^{12)}$. Experimental procedures were performed as described 
in previous reports ${ }^{12,14)}$. Two-dimensional gel electrophoresis (2-DE) and matrix-assisted laser desorption ionization time-of-flight/time-of-flight (MALDI-TOF/TOF) mass spectrometry were performed as reported in our previous studies $^{14,15)}$. Furthermore, to measure the phosphorylation of cofilin and LIM kinases, gastrocnemius muscle strips were isolated after specific intervals of cast immobilization and snap-frozen in liquid nitrogen. The samples were then homogenized in a sample buffer. The homogenate was centrifuged and the supernatant was collected. Proteins (45-50 $\mu \mathrm{g} /$ lane) were separated on $12 \%$ polyacrylamide sodium dodecylsulfate (SDS) gels and then transferred electrophoretically to a polyvinylidene fluoride membrane (Millipore; Bedford, MA, USA) ${ }^{13)}$. Anti-cofilin and anti-LIM kinase 1 and 2 antibodies were purchased from Santa Cruz (Santa Cruz, CA, USA). Antibody-specific bands were quantified using an image analyzer (BioRad). The present investigation conformed to the Guide for the Care and Use of Laboratory Animals published by the US National Institutes of Health (NIH Publication No. 85-23, revised 1996). The protocol of this study was approved by the Committee of Ethics in Research of the University of Yongin, in accordance with the terms of Resolution 5-1-20, December 2006. Data are expressed as means \pm SEM. The data were statistically evaluated using Student's t test for comparisons between two time points and by ANOVA for multiple comparisons. A p value of $<0.05$ was considered to be statistically significant.

\section{RESULTS}

The density of the cofilin expressed in the gastrocnemius muscles is shown in Fig. 1A. The phosphorylation of cofilin and LIM kinases was significantly diminished after 3, 7, 14, and 21 days of cast immobilization compared with the control group $(\mathrm{n}=3-4$, Fig. 1B, Table 1). However, the expression of cofilin was significantly increased after 3, 14, and 21 days of cast immobilization compared with the control group (n=3-4, Fig. 1B, Table 1).

\section{DISCUSSION}

Our previous study demonstrated that the transcriptional regulation of the protein ligase, muscle RING finger-1 (MuRF-1), is upregulated in rat gastrocnemius muscles, and is involved in the development of cast immobilization-induced muscle atrophy ${ }^{12}$. Mitogen-activated protein kinas- es, such as extracellular signal-regulated kinase $1 / 2$, stressactivated protein kinase/c-Jun $\mathrm{NH}_{2}$-terminal kinase, and p38 mitogen-activated protein kinase, are simultaneously involved in muscle atrophy induced by immobilization and cell starvation ${ }^{12,13)}$. Furthermore, in another study, we demonstrated that cast immobilization increases the expression of myoglobin in rat gastrocnemius muscles ${ }^{15)}$. These previous results suggest that changes in mitogen-activated protein kinase expression, causes myoglobin to adapt in response to physical stress, such as immobilization ${ }^{12-15)}$. Meanwhile, cofilin, one of the actin-depolymerizing factor/ cofilin family proteins, which includes cofilin-1, cofilin-2, and actin-depolymerizing factor (also called destrin) in mammals, binds to actin and plays a role in actin dynamics and reorganization, and other cellular functions ${ }^{3,16)}$. Cofilin activity is regulated by the phosphorylation of Ser-3 on its $\mathrm{NH}_{2}$-terminal ${ }^{17}$ ). Phosphorylation of cofilin is also performed by LIM kinases (LIM kinase 1 and LIM kinase 2 in mammals), and inhibits actin binding and severing, and the depolymerizing activities of cofilin ${ }^{9}, 16$ ). LIM kinases are named after LIM motif-containing protein kinases, and the name is derived from an acronym of three transcription factors, Lin11, Isl-1, and Mec-3 ${ }^{18)}$. The kinases responsible for this phosphorylation are Rho-associated protein kinase
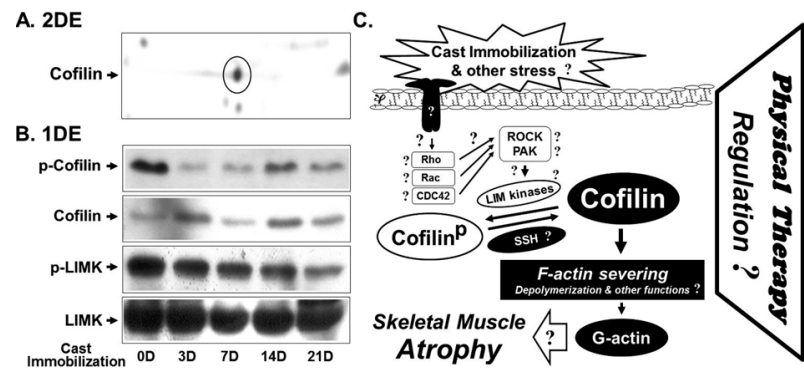

Fig. 1. Changes in phosphorylation of proteins, and a schematic representation of cellular responses to the immobilization. Proteomic (A) and immuno-blotting (B) analysis in the cast-immobilized skeletal muscle. 2DE and 1DE, two- and one-dimension gel electrophoresis; p-LIMK, phosphorylated LIM kinases; D, days; R, receptor; G-actin, globular actin; Rho-Rac-Cdc42, Rho family small GTPases; ROCK, Rho-associated protein kinase; PAK, p21-activated protein kinase; SSH, cofilin-specific phosphatase, slingshot.

Table 1. Changes in expression and phosphorylation of proteins in rat gastrocnemius muscles subjected to cast immobilization

\begin{tabular}{ccccc}
\hline $\begin{array}{c}\text { Experimental } \\
\text { period }\end{array}$ & $\begin{array}{c}\text { p-Cofilin } \\
(\%)\end{array}$ & $\begin{array}{c}\text { Cofilin } \\
(\%)\end{array}$ & $\begin{array}{c}\text { p-LIM kinases } \\
(\%)\end{array}$ & $\begin{array}{c}\text { LIM kinases } \\
(\%)\end{array}$ \\
\hline 0 day (control) & $100.0 \pm 0.0$ & $100.0 \pm 0.0$ & $100.0 \pm 0.0$ & $100.0 \pm 0.0$ \\
3 days & $7.7 \pm 1.8^{*}$ & $246.7 \pm 14.5^{*}$ & $73.3 \pm 12.0^{*}$ & $99.7 \pm 0.3$ \\
7 days & $19.0 \pm 4.9^{*}$ & $116.7 \pm 21.9$ & $58.3 \pm 7.3^{*}$ & $98.7 \pm 4.2$ \\
14 days & $33.3 \pm 10.1^{*}$ & $203.3 \pm 14.5^{*}$ & $60.0 \pm 7.6^{*}$ & $100.7 \pm 3.0$ \\
21 days & $26.7 \pm 10.1^{*}$ & $173.3 \pm 12.0^{*}$ & $45.0 \pm 10.4^{*}$ & $98.0 \pm 4.4$ \\
\hline
\end{tabular}

Means \pm SEM. p, phosphorylated protein; LIM kinase, a serine kinase. The basal levels of proteins and phosphorylated proteins in controls ( 0 days) were considered to be $100 \%$. *: vs. 0 day control, $\mathrm{p}<0.05$ 
(ROCK) and p21-activated protein kinase (PAK), which are downstream kinases of the Rho family small GTPases such as Rho, Rac, and Cdc42 ${ }^{19-21)}$. Whereas, the dephosphorylation of cofilin is mediated by the cofilin-specific phosphatase, slingshot $(\mathrm{SSH})^{7,8)}$ (Fig. 1C). Especially, cofilin is expressed in vascular smooth muscle cells and tissues, where it has been implicated in the regulation of cellular responses to reactive oxygen species (ROS), such as $\mathrm{H}_{2} \mathrm{O}_{2}{ }^{3}$ ) and the progression of bladder cancer ${ }^{22}$. Although cofilin is identified in skeletal muscle using proteomic analysis ${ }^{14)}$, it has not previously been reported that phosphorylation of cofilin is related to muscle atrophy induced by cast-immobilization. In the present study, we have demonstrated for the first time that decrease of phosphorylation of cofilin and LIM kinases is associated with skeletal muscle atrophy induced by cast immobilization. However, further systematic studies covering electrotherapy, neurotherapy, hydrotherapy and others are needed to confirm the mechanisms of cofilin and LIM kinases in various muscle atrophy conditions ${ }^{23-27)}$ (Fig. 1C). In summary, the phosphorylation of cofilin and LIM kinases decreased in cast-immobilized rat gastrocnemius muscles. The present results suggest that cast immobilization-induced atrophy may be mediated by LIM kinase and cofilin in rat gastrocnemius muscles.

\section{REFERENCES}

1) Bamburg JR, Harris HE, Weeds AG: Partial purification and characterization of an actin depolymerizing factor from brain. FEBS Lett, 1980, 121 178-182. [Medline] [CrossRef]

2) McGough A, Pope B, Chiu W, et al.: Cofilin changes the twist of F-actin: implications for actin filament dynamics and cellular function. J Cell Biol, 1997, 138: 771-781. [Medline] [CrossRef]

3) Lee CK, Park HJ, So HH, et al.: Proteomic profiling and identification of cofilin responding to oxidative stress in vascular smooth muscle. Proteomics, 2006, 6: 6455-6475. [Medline] [CrossRef]

4) Carlier MF, Laurent V, Santolini J, et al.: Actin depolymerizing factor (ADF/cofilin) enhances the rate of filament turnover: implication in actinbased motility. J Cell Biol, 1997, 136: 1307-1322. [Medline] [CrossRef]

5) Etienne-Manneville S, Hall A: Rho GTPases in cell biology. Nature, 2002 420: 629-635. [Medline] [CrossRef]

6) Kuhn TB, Meberg PJ, Brown MD, et al.: Regulating actin dynamics in neuronal growth cones by ADF/cofilin and rho family GTPases. J Neurobiol, 2000, 44: 126-144. [Medline] [CrossRef]

7) Huang TY, DerMardirossian C, Bokoch GM: Cofilin phosphatases and regulation of actin dynamics. Curr Opin Cell Biol, 2006, 18: 26-31. [Medline] [CrossRef]

8) Niwa R, Nagata-Ohashi K, Takeichi M, et al.: Control of actin reorganization by Slingshot, a family of phosphatases that dephosphorylate ADF/ cofilin. Cell, 2002, 108: 233-246. [Medline] [CrossRef]

9) Bernard O: Lim kinases, regulators of actin dynamics. Int J Biochem Cell
Biol, 2007, 39: 1071-1076. [Medline] [CrossRef]

10) Yang N, Higuchi O, Ohashi K, et al.: Cofilin phosphorylation by LIMkinase 1 and its role in Rac-mediated actin reorganization. Nature, 1998, 393: 809-812. [Medline] [CrossRef]

11) Arber S, Barbayannis FA, Hanser H, et al.: Regulation of actin dynamics through phosphorylation of cofilin by LIM-kinase. Nature, 1998, 393: 805-809. [Medline] [CrossRef]

12) Kim J, Won KJ, Lee HM, et al.: p38 MAPK participates in muscle-specific RING finger 1-mediated atrophy in cast-immobilized rat gastrocnemius muscle. Korean J Physiol Pharmacol, 2009, 13: 491-496. [Medline] [CrossRef]

13) Kim J, Kim B: Differential regulation of MAPK isoforms during castimmobilization induced atrophy in rat gastrocnemius muscle. J Phys Ther Sci, 2010, 22: 217-222. [CrossRef]

14) Kim J, Kim B: Identification of atrophy-related proteins produced in response to cast immobilization in rat gastrocnemius muscle. Mol Cell Toxicol, 2010, 6: 361-371.

15) Lee JU, Kim JH, Kim MY, et al.: Increase of myoglobin in rat gastrocnemius muscles with immobilization-induced atrophy. J Phys Ther Sci, 2013, 25: $1617-1620$.

16) dos Remedios CG, Chhabra D, Kekic M, et al.: Actin binding proteins: regulation of cytoskeletal microfilaments. Physiol Rev, 2003, 83: 433-473. [Medline]

17) Moriyama K, Iida K, Yahara I: Phosphorylation of Ser-3 of cofilin regulates its essential function on actin. Genes Cells, 1996, 1: 73-86. [Medline] [CrossRef]

18) Bach I: The LIM domain: regulation by association. Mech Dev, 2000, 91: 5-17. [Medline] [CrossRef]

19) Lee S, Helfman DM: Cytoplasmic p21Cip1 is involved in Ras-induced inhibition of the ROCK/LIMK/cofilin pathway. J Biol Chem, 2004, 279: 1885-1891. [Medline] [CrossRef]

20) Edwards DC, Sanders LC, Bokoch GM, et al.: Activation of LIM-kinase by Pak1 couples Rac/Cdc42 GTPase signalling to actin cytoskeletal dynamics. Nat Cell Biol, 1999, 1: 253-259. [Medline] [CrossRef]

21) Delorme V, Machacek M, DerMardirossian C, et al.: Cofilin activity downstream of Pak1 regulates cell protrusion efficiency by organizing lamellipodium and lamella actin networks. Dev Cell, 2007, 13: 646-662. [Medline] [CrossRef]

22) Chung H, Kim B, Jung SH, et al.: Does phosphorylation of cofilin affect the progression of human bladder cancer? BMC Cancer, 2013, 13: 45. [Medline] [CrossRef]

23) Jeon HJ, Kim JH, Hwang BY, et al.: Analysis of the sensory threshold between paretic and nonparetic sides for healthy rehabilitation in hemiplegic patients after stroke. Health, 2012, 4: 1241-1246. [CrossRef]

24) Kim MY, Kim JH, Lee JU, et al.: The effect of low frequency repetitive transcranial magnetic stimulation combined with range of motion exercise on paretic hand function in female patients after stroke. Neurosci Med, 2013, 4: 77-83. [CrossRef]

25) Choi BR, Kim JH, Lee JU, et al.: A pilot study on the effect of pelvic exercise on standing balance in patients with incomplete cervical spinal cord injury. Int J Clin Med, 2013, 4: 123-132. [CrossRef]

26) Kim JH, Choi YD, Kim MJ, et al.: Correlation between the changes in heat-induced digital infrared thermography imaging and body components in healthy volunteers. Toxicol Environ Health Sci, 2013, 5: 107-112. [CrossRef]

27) Kim JH, Lee LK, Lee WD, et al.: A review of signal transduction in mechanisms of smooth muscle contraction and its relevance for specialized physical therapy. J Phys Ther Sci, 2013, 25: 129-141. [CrossRef] 